\title{
Cryopreservation can assist gene flow on the Great Barrier Reef
}

\author{
Jonathan Daly ${ }^{1,2}$ (1) $\cdot$ Rebecca J. Hobbs ${ }^{3} \cdot$ Nikolas Zuchowicz $^{1,2} \cdot$ Justine K. O'Brien $^{3}$ • \\ Jessica Bouwmeester $^{1,2} \cdot$ Line Bay $^{4} \cdot$ Kate Quigley $^{4} \cdot$ Mary Hagedorn $^{1,2}$
}

Received: 17 March 2021 / Accepted: 8 November 2021/Published online: 24 January 2022

(C) The Author(s) 2022

\begin{abstract}
Maintaining genetic diversity and biodiversity is key to sustaining healthy ecosystems and their capacity for adaptation. Assisted Gene Flow (AGF) is a management approach to translocate adaptive genes among populations to restore faltering and at-risk habitats, especially on coral reefs. Cryopreserved sperm can facilitate AGF via selective breeding at a lower cost and with fewer risks than sourcing colonies from the wild or moving adult corals (translocation). Here, we present a proof-of-concept study demonstrating that cryopreserved sperm from northern and central Great Barrier Reef (GBR) locations can be used to make intrapopulation and interpopulation crosses to underpin AGF. The results of this study support the importance of assessing the concentration of motile sperm in post-thaw samples, with a minimum of approximately 30,000 motile cryopreserved sperm per egg required to achieve fertilisation. Mean per cent motility values post-collection and without artificial activation (northern colonies $14 \pm 3.2 \%$; central colonies $19 \pm 3.6 \%$ ) were considerably lower than previous observations of sperm from Acropora tenuis on the Great Barrier Reef, and may represent a lag effect from
\end{abstract}

Topic Editor Morgan S. Pratchett

Jonathan Daly

jondaly@zoo.nsw.gov.au

1 Center for Species Survival, Smithsonian Conservation Biology Institute, Smithsonian Institution, Front Royal, VA 22630, USA

2 Hawaii Institute of Marine Biology, University of Hawaii, Kaneohe, HI 96744, USA

3 Taronga Institute of Science and Learning, Taronga Conservation Society Australia, Mosman, NSW, Australia

4 Australian Institute of Marine Science, Townsville, QLD, Australia recent ocean warming events at the level of coral populations. Coral reefs with relatively high species and genetic diversity and coral cover are good places to preserve biodiversity through cryopreservation. Such cryo-collections build a genetic resource to optimise strategies available to reef managers to support natural recovery rates and reef restoration and adaptation efforts.

Keywords Selective breeding - Assisted gene flow . Coral $\cdot$ Sperm cryopreservation $\cdot$ Biobanking

\section{Introduction}

The survival of populations and species impacted by the effects of climate change will depend on their ability to adapt to rapidly changing environments. If environmental change is gradual then these adaptations can come about through genetic recombination (i.e. sexual reproduction) and natural selection for adaptive traits. When the rate of environmental change exceeds the capacity for adaptation species are likely to suffer severe population declines. For scleractinian corals, the effects of ocean warming, acute heat events, and subsequent mass bleaching have devastated species on reefs throughout the tropics (Eakin et al. 2019). Recent estimates suggest that a third of all remaining reef-building coral species are threatened with extinction (IPBES 2019). The negative impact of ocean warming on coral reproduction is also well-documented (Ward et al. 2000; Omori et al. 2001; Levitan et al. 2014; Hagedorn et al. 2016), which can reduce opportunities for genetic recombination and potentially result in long-term declines in the composition and amount of recruitment of new corals (Hughes et al. 2019). Consequently, corals around the world will likely experience a significant loss of 
genetic diversity over the coming decades that could ultimately diminish their capacity to adapt to changing conditions. Efforts to restore damaged coral populations and enhance resilience and adaptation all rely on the genetic diversity of source populations, and therefore securing biodiversity is a critical component of ensuring the continued function of coral reef ecosystems (Anthony et al. 2017; National Academies of Sciences 2018; Bay et al. 2019).

Assisted Gene Flow (AGF) is defined as the movement of organisms within the original species boundary and is increasingly considered as an option to facilitate rapid adaptation to climate change and assist the recovery of heavily impacted populations (Aitken and Whitlock 2013; van Oppen et al. 2014; National Academies of Sciences 2018; Quigley et al. 2019; Hagedorn et al. 2021). The translocation of adult coral colonies for AGF poses several challenges, including the increase in stress during transport that may negatively impact reproduction, the potential for transfer of disease or invasive species across regions, diminution of population density and diversity in source populations, and mismatches in reproductive timing of coral from the same species along an environmental gradient. Moreover, the costs associated with moving adult corals on the scale required to be effective is likely to be prohibitive for many of the major reef systems around the world. A safer and potentially more cost-effective way to facilitate the movement of genes and conserve genetic diversity would be to use cryopreserved gametes in combination with spawned material from wild individuals to support selective breeding and the development of diverse broodstock to support coral aquaculture and regional restoration activities (Hagedorn et al. 2012b; Silversides et al. 2012; Howell et al. 2020).

Cryopreservation, the storage of living cells at ultra-low temperatures, permits the transfer of potentially adaptive genetic material, thereby enabling reproduction and genetic recombination to occur between geographically or temporally isolated populations. The storage of cryopreserved gametes in biorepositories would also provide greater control over the selective breeding process by reducing the need for colonies to spawn on the same night or year, and would allow colonies to be used for reproduction in multiple years without re-collecting animals from the wild. Successful cryopreservation of coral sperm (Hagedorn et al. 2012a) has been demonstrated in more than 37 species from reefs around the world over the past ten years (Hagedorn and Daly, unpublished) and can be used to produce viable offspring (Hagedorn et al. 2017).

On the Great Barrier Reef (GBR), many species of coral occur across vast latitudinal and temperature gradients, with genetic evidence of population connectivity across this range (van Oppen et al. 2011; Cooke et al. 2020).
Reproductive connectivity has been demonstrated for Acropora millepora and Acropora tenuis across the northern, central, and southern regions of the GBR, where reproductively crossed larvae (Dixon et al. 2015) and juveniles (Quigley et al. 2020) showed heritability of heat tolerance. This suggests the potential for AGF to be used as a means of transferring heat-tolerant genes between populations across the GBR. The use of cryopreserved sperm to generate inter- and intra-specific crosses across regions could therefore provide an effective means to influence population connectivity on the GBR to confer resilience.

The use of cryopreservation to facilitate AGF in coral was recently demonstrated by Hagedorn et al. (2021), who crossed cryopreserved Acropora palmata sperm from three geographically isolated Caribbean populations (Florida, Curaçao, and Puerto Rico) with freshly collected eggs from Curaçao. These experiments included sperm that had been banked for over 10 years, and resulted in settled coral recruits that are currently over two years old. In Australia, sperm from GBR corals have been cryopreserved during the annual mass spawning since 2011 (Hagedorn et al. 2012a) with 29 species cryobanked to date (https://taronga. org.au/conservation-and-science/current-research/reefrecovery). The ability of cryopreserved sperm from GBR corals to fertilise fresh eggs has also been demonstrated (Hagedorn et al. 2017); however, interpopulation crosses using cryopreserved sperm have not been attempted on the GBR. The goal of the present study was therefore to undertake fertilisation experiments using cryopreserved sperm to facilitate interpopulation crosses between colonies of Acropora tenuis collected from populations in the northern and central regions of the GBR, and in doing so demonstrate proof-of-concept for using cryopreserved sperm to support AGF as a potential tool for reef restoration and adaptation programs along this reef system.

\section{Methods}

\section{Coral spawning}

Colonies of Acropora tenuis were collected in November 2018 from central and northern regions of the GBR (Fig. 1a, Great Barrier Reef Marine Park Authority Permit Numbers G12/35236.1 and G18/41667.1, respectively) by staff from the Australian Institute of Marine Science (AIMS) and Great Barrier Reef Legacy. Northern GBR colonies were collected from Curd Reef $\left(-12.5850^{\circ} \mathrm{S}\right.$, $\left.143.5115^{\circ} \mathrm{E}\right)$, Long Sandy Reef $\left(-12.5003^{\circ} \mathrm{S}\right.$, $\left.143.7848^{\circ} \mathrm{E}\right)$, and Sandbank No. 7 Reef $\left(-13.4362^{\circ} \mathrm{S}\right.$, $143.9714^{\circ} \mathrm{E}$ ), and central GBR colonies were collected from Davies Reef $\left(-18.8217^{\circ} \mathrm{S}, 147.6495^{\circ} \mathrm{E}\right)$ and Backnumbers Reef $\left(-18.5075^{\circ} \mathrm{S}, 147.1464^{\circ} \mathrm{E}\right)$ (Fig. 1). The 

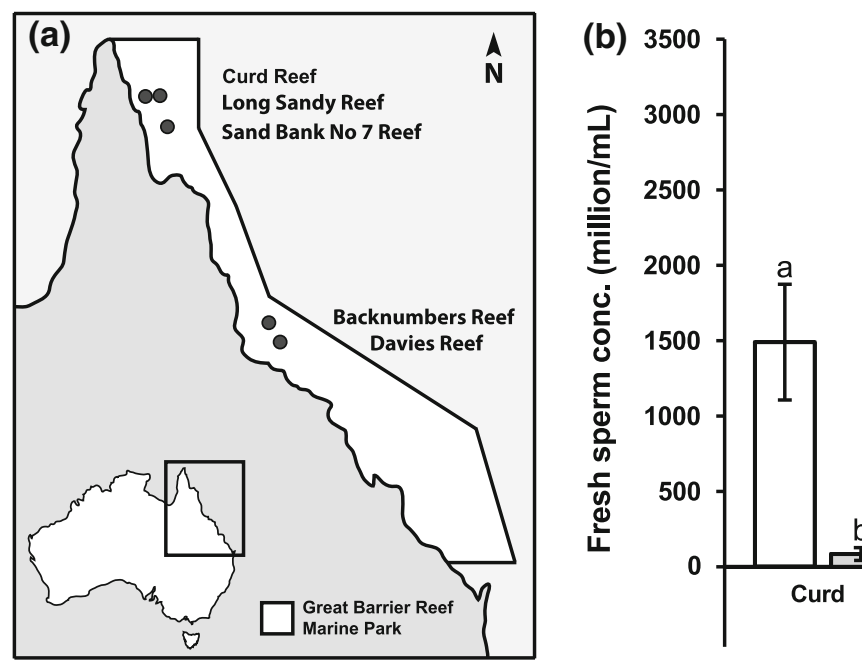

Fig. 1 Fresh sperm characteristics from Acropora tenuis colonies collected from five reefs in the northern and central Great Barrier Reef a were assessed using computer assisted sperm analysis to

annual mean temperatures for these reefs ranged between $\sim 28.7$ and $29.4^{\circ} \mathrm{C}$ (eReefs, 01/01/2013-28/02/2018, daily measurements at $1 \mathrm{~km}$ resolution). Colonies were brought to the National Sea Simulator (SeaSim) at AIMS, Townsville, for spawning, where they were kept in flow-through aquaria with natural light for up to two weeks prior to spawning on temperature profiles corresponding to their natal reefs.

On the night of spawning, colonies were transferred individually to $20-\mathrm{L}$ plastic bins containing $0.1-\mu \mathrm{m}$ filtered seawater (FSW) with no air or water flow, and monitored for signs of spawning. Gamete bundles were collected with transfer pipettes from the surface of the water into $50-\mathrm{mL}$ tubes, and then concentrated to a volume of five $\mathrm{mL}$ of bundles over five $\mathrm{mL}$ of seawater. Generally, in acroporid coral species, this provides a sperm concentration of $\sim 1 \times 10^{9}$ cells $/ \mathrm{mL}$. Bundles were allowed to break up with the aid of gentle agitation, and the sperm sample was passed through a 70- $\mu \mathrm{m}$ cell strainer (Corning, United States) to exclude eggs. Sperm quality metrics (total sperm concentration, motile sperm concentration-defined as the concentration of sperm that are swimming, and per cent motility) were estimated using a computer-assisted sperm analysis system (CASA-CEROS II, Hamilton Thorne, United States) calibrated for coral sperm analysis (Zuchowicz et al. 2021). Total and motile sperm concentration values were determined by assessing at least 200 individual sperm across a minimum of five microscope fields. Sperm from A. tenuis colonies from the central $(\mathrm{n}=14)$ and northern $(\mathrm{n}=17)$ regions of the GBR were assessed over five nights from 26-30 November 2018). $\square$ Total concentration $\square$ Motile concentration

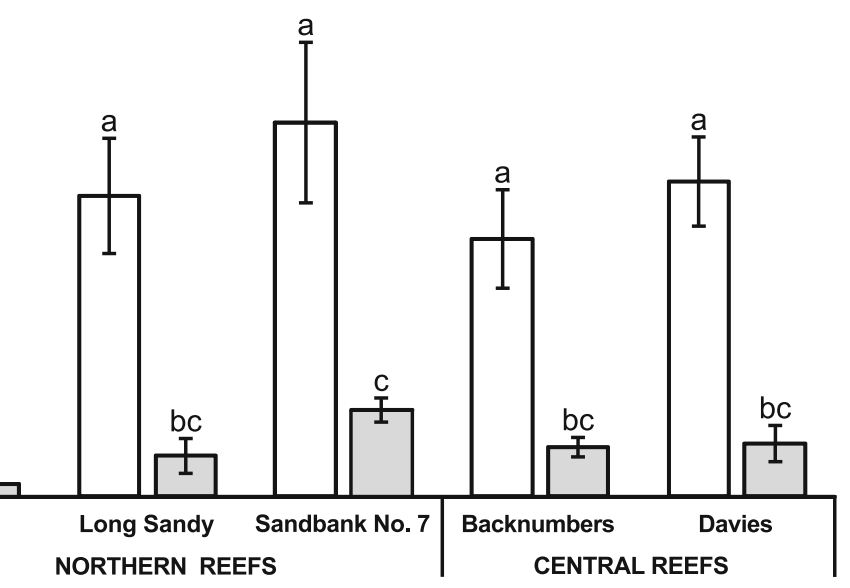

determine differences in total and motile concentrations b. Columns with different letters are significantly different (one-way ANOVA, $p<0.05)$

\section{Cryopreservation and fertilisation}

Fertilisation experiments were conducted on the nights of the 27th (night 1) and 29th (night 2) of November 2018 using gametes from 10 central and 11 northern colonies, representing two of the three nights when both groups spawned simultaneously. For cryopreservation, on each spawning night, sperm from individual colonies were assessed using CASA then combined in approximately equal amounts to create two pooled samples: one from northern GBR colonies (night $1 \mathrm{n}=6$; night $2 \mathrm{n}=5$ ) and one from central GBR colonies (night $1 \mathrm{n}=6$; night 2 $\mathrm{n}=4$ ). Aliquots of each sperm pool were combined $1: 1$ with 20\% dimethyl sulfoxide (DMSO) in FSW for final concentrations of $10 \%$ DMSO and at least $5 \times 10^{8} \mathrm{sperm} /$ $\mathrm{mL}$, then cryopreserved in $1.8-\mathrm{mL}$ cryovials $\left(\mathrm{Nunc}^{\mathrm{TM}} 1.8\right.$ $\mathrm{mL}$ internal thread cryovials, Cat. \# 377,267; $1.5 \mathrm{~mL}$ per cryovial, $\mathrm{n}=2-3$ cryovials per pool) in liquid nitrogen $\left(-196{ }^{\circ} \mathrm{C}\right)$ at a rate of $-20{ }^{\circ} \mathrm{C}$ per minute, as previously described (Hagedorn et al. 2012a). Remaining pooled sperm from each region were kept on the benchtop at room temperature $\left(26^{\circ} \mathrm{C}\right)$ for use in fertilisation experiments as the fresh sperm control within an hour of bundle break up. Cryopreserved samples for fertilisation experiments were thawed in a $37{ }^{\circ} \mathrm{C}$ seawater bath with gentle swirling for two minutes, after which post-thaw motility and concentration were assessed using CASA.

For fertilisation, aliquots of eggs from individual colonies (night $1: \mathrm{n}=6$ northern colonies, $\mathrm{n}=6$ central colonies; night $2: \mathrm{n}=5$ northern colonies, $\mathrm{n}=4$ central colonies) were transferred to separate wells in 6-well plates containing FSW (Table 1A). Transregional (NTH sperm $\times$ CEN eggs; CEN sperm $\times$ NTH eggs) and 
Table 1 Fertilisation experiments performed over two nights demonstrating interpopulation crosses in Acropora tenuis from northern and central regions of the GBR

\begin{tabular}{|c|c|c|c|c|c|c|c|c|}
\hline \multirow{2}{*}{$\begin{array}{l}\text { A } \\
\text { REGION }\end{array}$} & \multicolumn{4}{|c|}{ NIGHT $1($ NTH n $=6 ;$ CEN n $=6)$} & \multicolumn{4}{|c|}{ NIGHT $2($ NTH $n=5 ;$ CEN $n=4)$} \\
\hline & Eggs/well & Fresh & & Cryo & Eggs/well & Fresh & & Cryo \\
\hline NTH & $38.0 \pm 1.5$ & $1.9 \times 10$ & sperm/mL & $8.2 \times 10^{8}$ sperm $/ \mathrm{mL}$ & $44.7 \pm 1.1$ & $2.6 \times 10$ & erm $/ \mathrm{mL}$ & $1.5 \times 10^{9} \mathrm{sperm} / \mathrm{mL}$ \\
\hline CEN & $34.2 \pm 1.1$ & $1.1 \times 10$ & sperm $/ \mathrm{mL}$ & $4.7 \times 10^{8}$ sperm $/ \mathrm{mL}$ & $43.1 \pm 1.2$ & $1.0 \times 10$ & $\mathrm{erm} / \mathrm{mL}$ & $4.7 \times 10^{8} \mathrm{sperm} / \mathrm{mL}$ \\
\hline \multicolumn{9}{|l|}{ B } \\
\hline TREATMENT & & Control & Toxicity & Cryo & & Control & Tox & Cryo \\
\hline Sperm & & $5 \mu \mathrm{L}$ & $5 \mu \mathrm{L}$ & $10 \mu \mathrm{L}$ & & $5 \mu \mathrm{L}$ & $5 \mu \mathrm{L}$ & $50 \mu \mathrm{L}$ \\
\hline $10 \%$ DMSO & & - & $10 \mu \mathrm{L}$ & - & & - & $50 \mu \mathrm{L}$ & - \\
\hline
\end{tabular}

a Mean number of eggs per well and total sperm concentrations of fresh and cryopreserved sperm samples from northern and central GBR colonies. b Volumes of fresh and cryopreserved sperm and 10\% DMSO in FSW added to eggs for Control, Toxicity, and Cryo treatments. Total fertilisation volume was $5 \mathrm{~mL}$ in all experiments. Abbreviations follow descriptions given in the Methods section

regional $(\mathrm{CEN}$ sperm $\times$ CEN eggs; NTH sperm $\times$ NTH eggs) crosses were performed using cryopreserved pooled sperm samples, with fresh (untreated) sperm from the same pooled samples used as a control for each cross (Table 1a). To assess potential cryoprotectant effects on fertilisation, eggs from the same colonies were fertilised using pooled fresh sperm with the addition of $10 \%$ DMSO equivalent to the amount added with cryopreserved sperm (Table 1b), and 'no sperm' controls (i.e. unfertilized eggs) were used to rule out accidental or self-fertilisation of the eggs. The volume of FSW in each treatment was adjusted to achieve a final fertilisation volume of five $\mathrm{mL}$ in each well, and fertilisation success was assessed at the 2-4-cell stage (approximately 3-4 h post-fertilisation) by counting the number of developing embryos in each well.

Additional motility data from other years $(2011,2012$, 2014, 2016, 2019, and 2020) were collected by Hagedorn, Spindler, Hobbs, O'Brien, and Daly from central GBR A. tenuis colonies that spawned at AIMS (Table 2). From
2011 to 2016 motility was assessed by observing sperm under a phase contrast microscope and estimating the proportion of sperm moving forwards (Hagedorn et al. 2012b). Since 2018 motility data has been collected using CASA (Zuchowicz et al. 2021), with the addition of caffeine $(12 \mathrm{mM})$ for sperm activation prior to assessment in 2019 and 2020.

\section{Statistical analysis}

All data are presented as mean \pm S.E.M. Sperm motility data were analysed by one-way ANOVA with Tukey's post-hoc test using the GraphPad Prism statistical package for Mac (Version 7.0a). Differences were considered significant at a threshold value of $p<0.05$. Fertilisation data were analysed by Fisher's exact test of independence with pairwise comparisons using R (R Core Team 2019) with the "rcompanion" (Mangiafico 2019) package. Linear regression was used to determine the proportion of

Table 2 Comparison of sperm motility in Acropora tenuis pre- and post- back-to-back bleaching events in the central Great Barrier Reef in 2016 and 2017

\begin{tabular}{|c|c|c|c|c|c|c|c|}
\hline & \multicolumn{3}{|c|}{ PRE-2016/17 WARMING EVENT } & \multicolumn{4}{|c|}{ POST-2016/17 WARMING EVENT } \\
\hline & 2011 & 2012 & 2014 & 2016 & 2018 & 2019 & 2020 \\
\hline \multirow[t]{2}{*}{ Colonies $(\mathrm{n}=)$} & 3 & 9 & $4^{*}$ & 10 & 14 & 8 & 8 \\
\hline & \multicolumn{4}{|c|}{ MOTILITY (visual assessment) } & \multicolumn{3}{|c|}{ MOTILITY (CASA assessment) } \\
\hline Maximum & 90.0 & 91.0 & 82.0 & 80.0 & 38.8 & 96.2 & 84.5 \\
\hline Minimum & 80.0 & 73.0 & 68.0 & 40.0 & 0.1 & 44.1 & 44.4 \\
\hline Mean \pm SEM & $85.0 \pm 2.9$ & $85.8 \pm 1.9$ & $75.5 \pm 3.8$ & $52.0 \pm 4.7$ & $19.0 \pm 3.6$ & $80.6 \pm 6.9$ & $71.6 \pm 4.5$ \\
\hline Median & 85.0 & 87.0 & 76.0 & 45.0 & 19.4 & 88.5 & 74.7 \\
\hline
\end{tabular}

From 2011-2016 motility was assessed by observing sperm under a phase contrast microscope; since 2018 motility data has been collected using Computer Assisted Sperm Analysis. In 2019 and 2020, assessment included the addition of BSA and caffeine to activate sperm

*Assessments in 2014 include one individual colony and three pools of 3-5 colonies each 
fertilisation success that could be explained by the ratio of motile sperm per egg. Motile sperm per egg values were log-transformed and assumptions of homoscedasticity and normality of residuals were inspected visually. Linear regression analysis was conducted using $\mathrm{R}$ ( $\mathrm{R}$ Core Team 2019), with the "rcompanion" (Mangiafico 2019) and "ggplot2" (Wickham 2016) packages.

\section{Results and discussion}

Fertilisation was observed in crosses using both fresh and cryopreserved sperm from the two latitudes, confirming that cryopreserved sperm can be used to facilitate reproduction between northern and central populations of $A$. tenuis on the GBR. Sperm motility and sperm concentration showed greater variation among samples from the three northern reefs (Curd $7.6 \pm 3.9 \%$ motile, $1.5 \times 10^{9}$ sperm $/ \mathrm{mL}$; Long Sandy $12.4 \pm 4.4 \%$ motile, $2.0 \times 10^{9}$ sperm $/ \mathrm{mL}$; Sandbank No. $7 \quad 26.7 \pm 6.8 \%$ motile, $2.5 \times 10^{9} \mathrm{sperm} / \mathrm{mL}$ ) compared to samples from the two reefs in the central GBR (Davies $15.2 \pm 4.3 \%$ motile, $2.1 \times 10^{9} \mathrm{sperm} / \mathrm{mL}$; Backnumbers $24.2 \pm 6.0 \%$ motile, $1.7 \times 10^{9} \mathrm{sperm} / \mathrm{mL}$ ) (Fig. 1b). Moreover, motility values (Fig. 1b) were lower across all samples compared to previously collected A. tenuis samples from the GBR (Table 2).

Prior to the back-to-back ocean warming events in 2016 and 2017, the motility of sperm collected from A. tenuis from the central GBR for cryopreservation ranged from $68.0 \%$ to $91.0 \%$, with mean motilities of $85.0 \pm 2.9 \%$ (2011), $85.8 \pm 1.9 \% \quad(2012)$ and $75.5 \pm 3.8 \%$ (2014) observed during that period (Table 2). Mean motilities in $A$. tenuis were observed to be much lower in the years immediately following the 2016/17 ocean warming events (2016: $52.0 \pm 4.7$; 2018: $19.0 \pm 3.6 \%$ ), and were back to around pre-warming levels in $2019(80.6 \pm 6.9 \%)$ and $2020(71.6 \pm 4.5 \%)$ (Table 2). However, it is important to note that sperm motility remained relatively low in some colonies in 2019 and 2020 (minimum motilities 2019: $44.1 \%$; $202044.4 \%$ ), indicating possible variation among colonies in the impact of or recovery from those ocean warming events.

Regardless of the lower overall motility, the fertilisation rate using fresh sperm was greater than $85.7 \pm 2.5 \%$ on the first night of spawning (27 November) and $98.4 \pm 1.1$ on night 2 for all the crosses tested, but was more variable $(0.4 \pm 0.4-52.4 \pm 12.5 \%)$ using cryopreserved sperm (Figs. 2, 3). On the first night, standard fertilisation protocols for cryopreserved coral sperm were used (Hagedorn et al. 2017). However, the sperm volume adjustment used to account for diminished post-thaw sperm quality (i.e. adding $2 \times$ the volume of that used for fresh sperm;
Table 1b) was insufficient to overcome the low post-thaw motile concentration of these samples (central: $2.3 \times 10^{7}$ sperm $/ \mathrm{mL}, \quad 5.1 \%$ of total concentration; northern: $2.2 \times 10^{7}$ sperm $/ \mathrm{mL}, 2.7 \%$ of total concentration) and poor fertilisation was observed in all crosses using cryopreserved sperm $(0.4 \pm 0.4-4.3 \pm 0.7 \%$; Fig. 2$)$. The volume of cryopreserved sperm added for fertilisation was subsequently increased for crosses performed on night 2 $(10 \times$ the volume of fresh sperm; Table $1 b)$. Using cryopreserved sperm from northern colonies on night 2 resulted in $52.4 \pm 12.5 \%$ fertilisation for northern eggs and slightly lower $(44.9 \pm 13.0 \%)$ for central eggs (Fig. 2). In contrast, fertilisation rates were more than three-fold lower when cryopreserved sperm from central colonies were used with eggs from northern $(14.2 \pm 4.1 \%)$ and central $(2.7 \pm 0.5 \%$ ) colonies (Fig. 2). These fertilisation rates reflected the post-thaw sperm parameters observed for cryopreserved sperm from the central and northern GBR colonies, with the pooled central GBR sample showing a three-fold lower motile concentration $\left(2.6 \times 10^{7}\right.$ sperm/ $\mathrm{mL}, 5.5 \%$ of total concentration) compared to the northern GBR pooled sample $\left(7.9 \times 10^{7} \mathrm{sperm} / \mathrm{mL}, 5.5 \%\right.$ of total concentration). This emphasises the importance of measuring the motile concentration of sperm, especially postthaw, as samples with the same per cent motility can have different motile concentrations resulting in substantially different fertilisation outcomes.

The difference in post-thaw motile concentration between northern and central GBR colonies on night 2 was somewhat unexpected given that the fresh central GBR pooled sperm sample had a higher motile concentration $\left(5.1 \times 10^{8} \mathrm{sperm} / \mathrm{mL}\right)$ than the fresh pooled sample from the northern colonies $\left(8.6 \times 10^{7} \mathrm{sperm} / \mathrm{mL}\right)$. Nevertheless, after cryopreservation these central samples showed a $95 \%$ decline in motile sperm concentration, compared to an $8 \%$ post-thaw decline in the sample from northern colonies. While the 40-50\% fertilisation rate achieved using cryopreserved sperm from northern colonies on night 2 was comparable to rates previously reported for cryopreserved coral sperm (Hagedorn et al. 2017), the fertilisation rate achieved using cryopreserved sperm from central colonies was much lower than would be expected. This was likely due to differences in the post-thaw sperm quality between samples from the two regions, as reflected by fertilisation rate and the ratio of motile sperm:egg (Fig. $3 ; \mathrm{R}^{2}=0.643$, $p<2.2 \mathrm{e}-16)$.

Comparison of fertilisation rates with motile sperm:egg ratios in fresh and cryopreserved sperm showed that, in general, a minimum of approximately 30,000 motile sperm per egg was required to achieve fertilisation using cryopreserved sperm. This threshold was reached on night 2 using cryopreserved sperm from northern colonies but not from central colonies despite the increased volume of 
Fig. 2 Fertilisation success of interpopulation crosses performed in Acropora tenuis from central and northern regions of the Great Barrier Reef on night 1 (white bars) and night 2 (grey bars) using fresh and cryopreserved sperm. Columns with different letters are significantly different (oneway ANOVA, $p<0.05)$

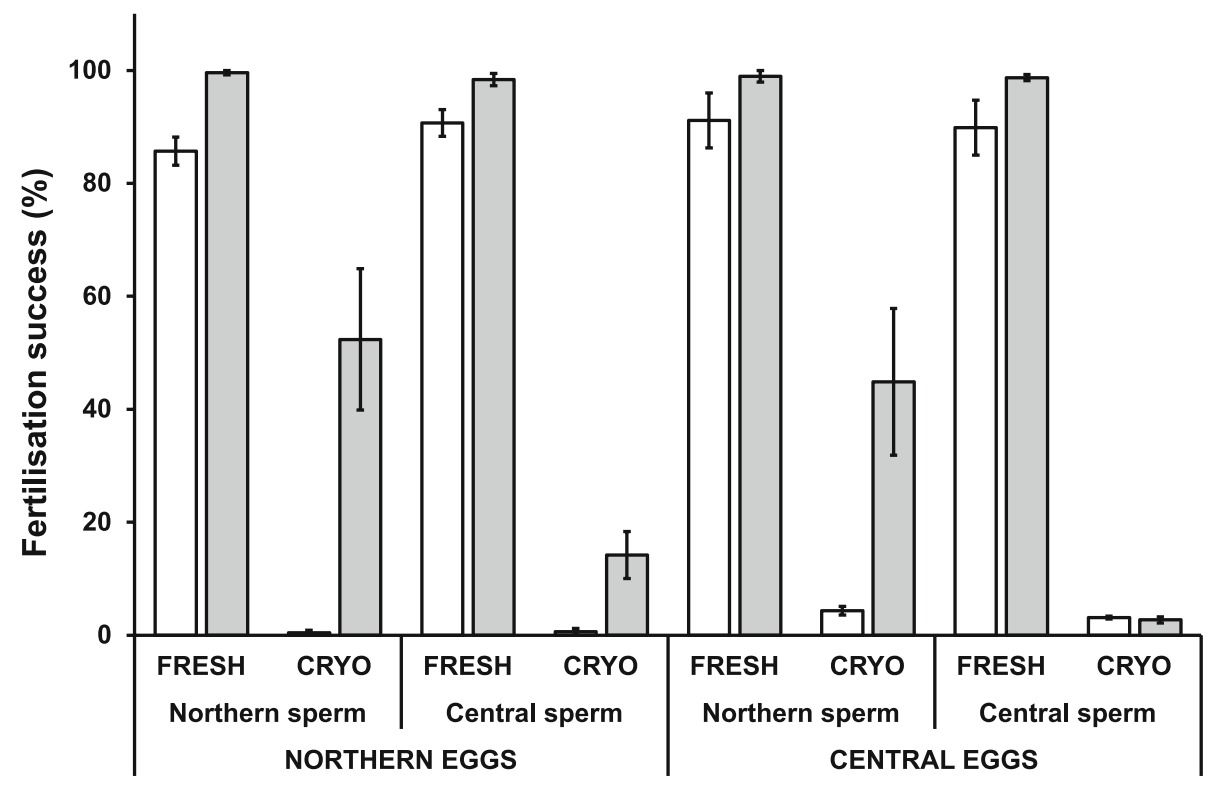

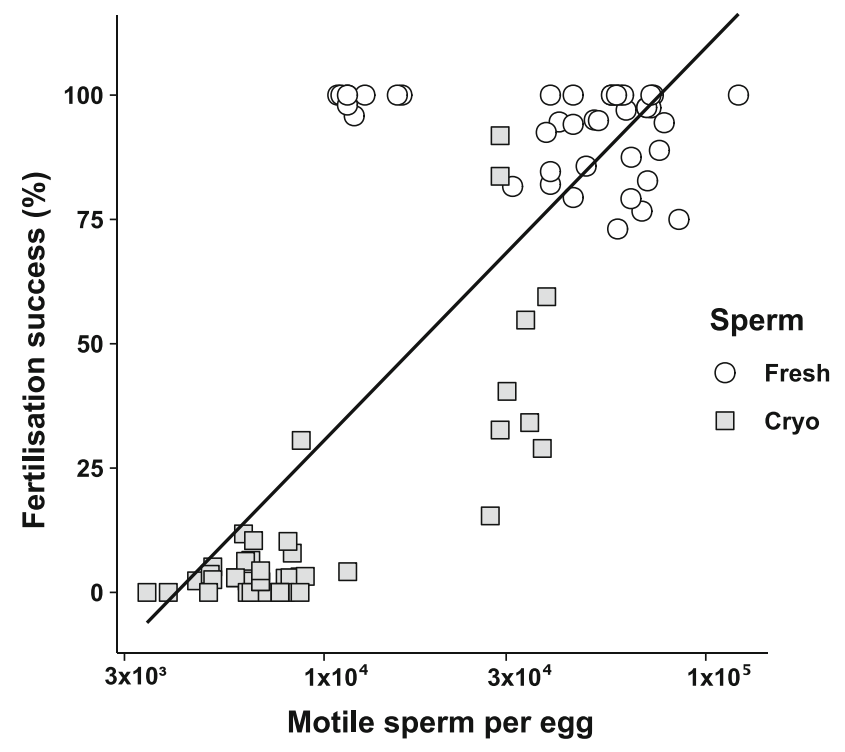

Fig. 3 Relationship between fertilisation success (y-axis) and the ratio of motile sperm per egg (x-axis, logarithmic) for Acropora tenuis interpopulation crosses performed on nights 1 and 2 . $\mathrm{R}^{2}=0.643, p<2.2 \mathrm{e}-16$

sperm added, and was not met in any crosses using cryopreserved sperm on night 1 . These results underscore the importance of indexing the volume of sperm added for fertilisation to the motile sperm concentration value when utilising cryopreserved sperm for coral reproduction, as is standard practice in human and other animal IVF systems (e.g. O'Brien and Roth 2000). In general, the use of cryopreserved coral sperm for fertilisation has aimed to minimise the volume of post-thaw sperm added due to concerns that the cryoprotectant $(10 \%$ DMSO $\mathrm{v} / \mathrm{v}$ in the cryopreserved sample) may impair fertilisation (Hagedorn et al. 2017). However, fertilisation rates in the toxicity controls for pooled sperm from central (night 1: $90.4 \pm 2.5$; night $2: 99.3 \pm 1.2$ ) and northern (night 1 : $89.9 \pm 2.9$; night 2: $98.7 \pm 2.0$ ) colonies using DMSO concentrations equivalent to cryopreserved sperm $(0.1 \%$ DMSO v/v in the fertilisation volume) were not significantly different from those observed using fresh sperm among any of the crosses (one-way ANOVA, $p>0.05$ ), indicating that the cryoprotectant had no significant effect on fertilisation in the present study. Although, increasing the amount of cryopreserved sperm added for fertilisation had a positive effect in this study, it is likely that there is an upper limit to the improvements in fertilisation success that can be gained by increasing the concentration of cryopreserved sperm used, and this should be considered as part of future studies. Another important point to consider for future studies is the grow-out of coral colonies produced using cryopreserved material. Previous studies have shown that A.tenuis and A.millepora larvae produced from cryopreserved sperm are able to settle and metamorphose at the same rate as larvae from fresh sperm (Hagedorn et al. 2017), but unfortunately in the present study we did not have the capacity to follow the cryopreserved crosses beyond fertilisation. The growth of coral juveniles produced using cryopreserved material through ontogeny and into reproductive maturity has not yet been reported, but will be an important step in demonstrating the utility of cryopreserved material in genetic management for coral.

Ocean warming can negatively impact a variety of reproductive parameters in corals, and declines in gamete quality and fertilisation have been reported in the years following major ocean warming and bleaching events (Ward et al. 2000; Omori et al. 2001; Levitan et al. 2014; 
Hagedorn et al. 2016). Importantly, in some cases these negative impacts can occur in corals that do not show obvious signs of bleaching, and can persist for a number of years following the warming event (Levitan et al. 2014; Hagedorn et al. 2019). Since both the northern and central regions of the GBR experienced extensive ocean warming, bleaching, and mortality in 2016 and 2017 (Hughes et al. 2017, 2019), it is possible that the diminished sperm motility and responses to cryopreservation observed in the present study were influenced by these events. The reasons for differences in fertilisation success observed in postthaw gametes from northern and central colonies are unclear, but may be a reflection of differences in accumulated heat stress of the 2016 and 2017 warming events, since the northern region was predominantly impacted in 2016 and the central region in 2017 (Hughes et al. 2018). As such, gametogenesis in the northern colonies may have recovered somewhat from the 2016 warming and been less impacted in the months leading up to spawning in 2018. As the survivors of the severe ocean warming event on the northern GBR in 2016, it is also possible that the northern colonies represented were more heat tolerant and better adapted to subsequent warming in 2017, which was a consideration in the selection of the northern GBR collection sites (Quigley et al. 2021). In this regard, cryopreservation may be acting as a 'stress test', revealing issues in gamete quality that may have become apparent later in larval development and recruitment using non-cryopreserved gametes. Cryopreservation does impact fertilisation success (Hagedorn et al. 2012b) even in healthy systems, but it does not impact settlement and juvenile development (Hagedorn et al. 2017). Moreover, AGF A. palmata created using cryopreserved sperm demonstrated normal settlement and juvenile development (Hagedorn et al. 2021), suggesting cryopreservation will be a valuable technique to support selective breeding for future coral restoration and adaption interventions.

As coral reefs continue to be impacted by climate change, a range of novel interventions are increasingly proposed, considered, or implemented around the globe. Genetic interventions that seek to preserve and enhance genetic diversity could become an important means of future-proofing reefs, restoring populations, and enhancing resilience and biodiversity to support the health of coral reefs in an increasingly uncertain future. This proof-ofconcept study showed that cryopreserved sperm can be used to cross colonies from different latitudes on the GBR, albeit at lower success rates than those with fresh material. We also detected potential signatures of environmental stress in sperm quality. These results inform ongoing strategic cryobanking effort and underpin further research into the methods and feasibility of Assisted Gene Flow via selective breeding on the Great Barrier Reef.
Acknowledgements The authors would like to acknowledge the Traditional Owners of the Great Barrier Reef and thank the Lama Lama people for permission to collect corals and bring them to AIMS National SeaSimulator. The authors would also like to thank Great Barrier Reef Legacy, who provided essential in-kind support, expertise, and personnel to allow live corals for this project to be collected and flown back from the remote far northern Great Barrier Reef aboard their "Search For Solutions" collaborative science expedition in 2018, AIMS for passage on the central voyage, and Carlos AlvarezRoa, Veronique Mocellin, Sam Noonan, Trinity Georgetown, and SeaSim staff for their assistance in the field. This project was funded through the National Environmental Science Program (Project 4.4 to Bay and Quigley), the Great Barrier Reef Foundation ("Biobanking to facilitate trans-regional geneflow in acroporid corals of the Great Barrier Reef" to Daly, Hobbs, Zuchowicz and O'Brien), Taronga Conservation Society Australia, Smithsonian Institution, the Paul M. Angell Family Foundation, the Seaver Institute, and the Australian Institute of Marine Science. This manuscript has contribution number 1871 from the Hawaii Institute of Marine Biology.

\section{Declarations}

Conflicts of interest The authors declared that there is no conflict of interest.

Open Access This article is licensed under a Creative Commons Attribution 4.0 International License, which permits use, sharing, adaptation, distribution and reproduction in any medium or format, as long as you give appropriate credit to the original author(s) and the source, provide a link to the Creative Commons licence, and indicate if changes were made. The images or other third party material in this article are included in the article's Creative Commons licence, unless indicated otherwise in a credit line to the material. If material is not included in the article's Creative Commons licence and your intended use is not permitted by statutory regulation or exceeds the permitted use, you will need to obtain permission directly from the copyright holder. To view a copy of this licence, visit http://creativecommons. org/licenses/by/4.0/.

\section{References}

Aitken SN, Whitlock MC (2013) Assisted gene flow to facilitate local adaptation to climate change. Annu Rev Ecol Evol Syst 44:367-388

Anthony K, Bay LK, Costanza R, Firn J, Gunn J, Harrison P, Heyward A, Lundgren P, Mead D, Moore T, Mumby PJ, van Oppen MJH, Robertson J, Runge MC, Suggett DJ, Schaffelke B, Wachenfeld D, Walshe T (2017) New interventions are needed to save coral reefs. Nature Ecology \& Evolution 1:1-3

Bay L, Rocker M, Boström-Einarsson L, Babcock R, Buerger P, Cleves P, Harrison D, Negri A, Quigley K, Randall C, van Oppen M, Webster N (2019) Reef restoration and adaptation program: intervention technical summary. A report provided to the Australian Government by the Reef Restoration and Adaptation Program $89 \mathrm{pp}$

Cooke I, Ying H, Forêt S, Bongaerts P, Strugnell J, Simakov O, Zhang J, Field MA, Rodriguez-Lanetty M, Bell SC, Bourne DG, van Oppen MJ, Ragan MA, Miller DJ (2020) Signatures of selection in the coral holobiont reveal complex adaptations to inshore environments driven by Holocene climate change. bioRxiv:2020.2002.2025.951905

Dixon GB, Davies SW, Aglyamova GA, Meyer E, Bay LK, Matz MV (2015) Genomic determinants of coral heat tolerance across latitudes. Science 348:1460-1462 
Eakin CM, Sweatman HPA, Brainard RE (2019) The 2014-2017 global-scale coral bleaching event: insights and impacts. Coral Reefs 38:539-545

Hagedorn M, Carter VL, Henley EM, van Oppen MJH, Hobbs R, Spindler RE (2017) Producing coral offspring with cryopreserved sperm: a tool for coral reef restoration. Sci Rep 7:1-9

Hagedorn M, Carter VL, Lager C, Camperio Ciani JF, Dygert AN, Schleiger RD, Henley EM (2016) Potential bleaching effects on coral reproduction. Reprod Fertil Dev 28:1061-1011

Hagedorn M, Carter V, Martorana K, Paresa MK, Acker J, Baums IB, Borneman E, Brittsan M, Byers M, Henley M, Laterveer M, Leong J-A, McCarthy M, Meyers S, Nelson BD, Petersen D, Tiersch T, Uribe RC, Woods E, Wildt D (2012b) Preserving and using germplasm and dissociated embryonic cells for conserving caribbean and pacific coral. PLoS ONE 7:e33354-e33313

Hagedorn M, van Oppen MJH, Carter V, Henley M, Abrego D, PuillStephan E, Negri A, Heyward A, MacFarlane D, Spindler R (2012a) First frozen repository for the Great Barrier Reef coral created. Cryobiology 65:157-158

Hagedorn M, Spindler R, Daly J (2019) Cryopreservation as a Tool for Reef Restoration: 2019. In: Comizzoli P, Brown J, Holt W (eds) Reproductive Sciences in Animal Conservation Advances in Experimental Medicine and Biology, vol 1200 Springer, Cham

Hagedorn M, Page CA, O’Neil KL, Flores DM, Tichy L, Conn T, Chamberland VF, Lager C, Zuchowicz N, Lohr K, Blackburn H, Vardi T, Moore J, Moore T, Baums IB, Vermeij MJA, Marhaver KL (2021) Assisted gene flow using cryopreserved sperm in critically endangered coral. Proc Natl Acad Sci U S A 118

Howell LG, Frankham R, Rodger JC, Witt RR, Clulow S, Upton RMO, Clulow J (2020) Integrating biobanking minimises inbreeding and produces significant cost benefits for a threatened frog captive breeding programme. Conserv Lett. https://doi.org/ 10.1111/conl.12776

Hughes TP, Kerry JT, Baird AH, Connolly SR, Chase TJ, Dietzel A, Hill T, Hoey AS, Hoogenboom MO, Jacobson M, Kerswell A, Madin JS, Mieog A, Paley AS, Pratchett MS, Torda G, Woods RM (2019) Global warming impairs stock-recruitment dynamics of corals. Nature 568:1-14

Hughes TP, Kerry JT, Connolly SR, Baird AH, Eakin CM, Heron SF, Hoey AS, Hoogenboom MO, Jacobson M, Liu G, Pratchett MS, Skirving W, Torda G (2018) Ecological memory modifies the cumulative impact of recurrent climate extremes. Nat Clim Chang 9:1-7

Hughes TP, Kerry JT, Álvarez-Noriega M, Álvarez-Romero JG, Anderson KD, Baird AH, Babcock RC, Beger M, Bellwood DR, Berkelmans R, Bridge TC, Butler IR, Byrne M, Cantin NE, Comeau S, Connolly SR, Cumming GS, Dalton SJ, Diaz-Pulido G, Eakin CM, Figueira WF, Gilmour JP, Harrison HB, Heron SF, Hoey AS, Hobbs J-PA, Hoogenboom MO, Kennedy EV, Kuo C-y, Lough JM, Lowe RJ, Liu G, McCulloch MT, Malcolm HA, McWilliam MJ, Pandolfi JM, Pears RJ, Pratchett MS, Schoepf V, Simpson T, Skirving WJ, Sommer B, Torda G, Wachenfeld DR, Willis BL, Wilson SK (2017) Global warming and recurrent mass bleaching of corals. Nature 543:373-377

IPBES (2019) Global assessment report of the Intergovernmental Science-Policy Platform on Biodiversity and Ecosystem Services. Brondízio, E. S., Settele, J., Díaz, S., Ngo, H. T. (eds).
IPBES secretariat, Bonn, Germany. 1144 pages. ISBN: 978-3947851-20-1

Levitan DR, Boudreau W, Jara J, Knowlton N (2014) Long-term reduced spawning in Orbicella coral species due to temperature stress. Mar Ecol Prog Ser 515:1-10

Mangiafico S (2019) rcompanion: Functions to support extension education program evaluation. $\mathrm{R}$ package version 2.3.7. https:// CRAN.R-project.org/package=rcompanion

National Academies of Sciences, Engineering, and Medicine (2018) A research review of interventions to increase the persistence and resilience of coral reefs, Washington, D.C. $209 \mathrm{pp}$

O'Brien JK, Roth TL (2000) Functional capacity and fertilizing longevity of frozen-thawed scimitar-horned oryx (Oryx dammah) spermatozoa in a heterologous in vitro fertilization system. Reprod Fertil Dev 12:413-421

Omori M, Fukami H, Kobinata H, Hatta M (2001) Significant drop of fertilization of Acropora corals in 1999: An after-effect of heavy coral bleaching? Limnol Oceanogr 46:704-706

van Oppen MJH, Peplow LM, Kininmonth S, Berkelmans R (2011) Historical and contemporary factors shape the population genetic structure of the broadcast spawning coral, Acropora millepora, on the Great Barrier Reef. Mol Ecol 20:4899-4914

van Oppen MJH, Puill-Stephan E, Lundgren P, Death G, Bay LK (2014) First-generation fitness consequences of interpopulational hybridisation in a Great Barrier Reef coral and its implications for assisted migration management. Coral Reefs 33:607-611

Quigley KM, Bay LK, Oppen MJH (2019) The active spread of adaptive variation for reef resilience. Ecol Evol 27:1342-1314

Quigley KM, Marzonie M, Ramsby B, Abrego D, Milton G, van Oppen MJH, Bay LK (2021) Variability in fitness trade-offs amongst coral juveniles with mixed genetic backgrounds held in the wild. Front Mar Sci. https://doi.org/10.3389/fmars.2021. 636177

Quigley K, Randall C, van Oppen M, Bay L (2020) Assessing the role of historical temperature regime and algal symbionts on the heat tolerance of coral juveniles. Biol Open. https://doi.org/10.1242/ bio.047316

R Core Team (2019) R: A language and environment for statistical computing. R Foundation for Statistical Computing, Vienna, Austria

Silversides FG, Purdy PH, Blackburn HD (2012) Comparative costs of programmes to conserve chicken genetic variation based on maintaining living populations or storing cryopreserved material. Br Poult Sci 53:599-607

Ward S, Harrison P, Hoegh-Guldberg O (2000) Coral bleaching reduces reproduction of scleractinian corals and increases susceptibility to future stress. 9th International Coral Reef Symposium

Wickham H (2016) ggplot2: Elegant graphics for data analysis. Springer, New York

Zuchowicz N, Daly J, Bouwmeester J, Lager C, Henley EM, Nuñez Lendo CI, Hagedorn M (2021) Assess Coral Sperm Motil Sci Rep 11:61

Publisher's Note Springer Nature remains neutral with regard to jurisdictional claims in published maps and institutional affiliations. 